\title{
206
}

\section{THE HEREDITARY AND FAMILIAL ASPECTS OF EXOPHTHALMIC GOITRE AND NODULAR GOITRE}

\author{
BY LAURENCE MARTIN (From \\ Addenbrooke's Hospital, Cambridge) \\ With a genetical note by R. A. Fisher \\ (Department of Genetics, Cambridge University) \\ ${ }^{1}$ Received August 5, 1945.

\section{Introduction}

THE hereditary and familial aspects of exophthalmic goitre, although not entirely disregarded, have not apparently been closely studied in the past. They have most often received attention in connexion with the occurrence of exophthalmic goitre among children (Cockayne, 1928; Atkinson, 1938; Moolten and Bruger, 1942) while isolated families notably affected by the disease are also on record. (Wild, 1886 ; Pern, 1911 ; Souques and Lermoyez, 1919; Climenko, 1920; Morrison, 1928.) Such restricted studies have in general contributed little to our knowledge, for some have consisted at the most of a few spectacular family trees from which general genetical conclusions could scarcely be drawn, while others have been encyclopaedic reviews of the literature without providing any decisive information.

Joll (1932) stated that there was no real evidence that exophthalmic goitre was usually hereditary and Means (1937) could allow only that hereditary factors might be important in production of the disease. No detailed study of the families of a large series of adult exophthalmic goitre patients appears to exist, although Mackenzie (1916) noted affected relatives in 44 of 438 cases and Gardiner-Hill (1934) recorded six per cent. of 100 cases with a history of the disease in ascendants and nine per cent. with affected siblings. In the case of nodular goitre, whether non-toxic or associated with secondary thyrotoxicosis, any hereditary or familial factors are bound up with those of simple colloid goitre which is a prerequisite antecedent of a nodular goitre. As will be discussed later the factor of environment is so entangled with any possible hereditary trait that a clear separation of the two would be extremely difficult. The object of the present paper is to set out the results of a study of the familial and hereditary factors in an adult series of 90 cases of exophthalmic goitre (primary thyrotoxicosis) and 111 cases of nodular goitre, both toxic (secondary thyrotoxicosis) and non-toxic, and to examine the information obtained from both types of the disease. 


\section{Material}

All the cases have been personally questioned and examined. Detailed family trees were obtained from 35 cases of exophthalmic goitre and 50 cases of nodular goitre, while details of any relatives affected by goitre were noted in the remainder. Information about possible consanguinity of the patients' parents is not available because it was not anticipated at the time of collection of data that statements of consanguinity might be valuable. On reviewing the results obtained, it is clear that such information might have been pertinent in connexion with the finding of a factor of recessive inheritance, if consanguineous marriages of the patients' parents had exceeded five per cent. The patients were all of the hospital class; 135 were drawn from the Borough of Cambridge, 55 from the adjacent urban and rural districts of Cambridgeshire, Isle of Ely, Hertfordshire, Suffolk, Essex, Norfolk, and Bedfordshire, 10 from London, and one from Scotland. The 174 woman patients were almost all occupied in their homes; only 25 had other work as clerks, shopassistants, or domestic servants. Of the 27 male patients 17 were agricultural workers, while the remainder were artisans or shopkeepers and one was a railway signalman. All the patients were adults, and cases of puberty goitre were excluded from the series partly because evidence of thyrotoxicosis was often transient or doubtful and partly because of the difficulty in assigning such cases either to the primary or secondary category of thyrotoxicosis.

Cases of toxic and non-toxic nodular goitre have been included together under the description of nodular goitre for the following reasons:

(i) A simple colloid goitre is the starting-point of both types, hence any hereditary or familial trait is likely to be the same for each.

(ii) A definite diagnosis of thyrotoxicosis is frequently difficult in patients with a nodular goitre and there are many doubtful or borderline cases.

(iii) Thyrotoxic symptoms are liable to develop at any time in the possessor of a nodular goitre, and a certain proportion of these considered to be nonthyrotoxic at the time of examination might well become thyrotoxic at a later date.

The broad classification of patients into exophthalmic goitre and nodular goitre rested upon the history, clinical signs, and histological examination of the goitres from those submitted to thyroidectomy.

\section{General Considerations}

A study of this kind should ideally comprise examination of all the known relatives of each patient, but this was impracticable and reliance has necessarily been placed upon the patients' statements. In some instances several members of one family who were affected by goitres have been seen because they sought treatment at Addenbrooke's Hospital, and occasionally a relative who accompanied a patient to hospital was also found to have a goitre, but these chance occurrences were infrequent. Nevertheless, there are good grounds for believing what goitre patients say about their relatives in respect 
of exophthalmic goitre in particular. A patient with exophthalmic goitre has striking outward appearances and is quick to observe or remember similar manifestations in a relative, so that a family history of exophthalmic goitre is usually reliable. A goitre is generally a fairly obvious phenomenon and it carries no stigma in lay minds so that, in contradistinction to insanity or tuberculosis, patients do not hesitate to volunteer information. Some patients knew that a relative had been operated upon for a goitre but did not know its type, while others could not go further than report a relative with a lump in the neck. In such instances exophthalmic goitre could be inferred or excluded by questioning, provided that the patient had actually seen the affected relative, but it was sometimes impossible to be certain whether a relative's goitre was toxic or non-toxic, although an operation on it suggested the former. It is evident that the reported number of affected relatives is likely to be smaller than the actual number, for small goitres are sometimes not obvious to laymen, as is shown by those found in patients who were unaware of their presence. There is also the unpredictable chance that the young and unaffected children of goitre patients might develop a goitre or thyrotoxicosis later in life.

Having regard to these considerations the following classification was adopted for the goitres of affected relatives:

Known exophthalmic goitre (Ex. G.)

Known toxic goitre (T. G.)

Known simple goitre (S. G.)

Goitre, not known to be toxic or presumed simple (G.). The toxic goitre group probably included most cases of toxic nodular goitre in which exophthalmos is usually slight or absent.

\section{Results}

The results are derived from two sources, either from data from all the cases or only from those whose family trees were known. From the former, crude information is obtained concerning the number and relationships of the various relatives affected, and from the latter, more detailed information concerning siblings. Information about mothers and fathers could reasonably be accepted from all the cases whether full family trees were available or not.

Tables I and II show the numbers and relationships of the 88 affected relatives of 90 cases of exophthalmic goitre and 111 cases of nodular goitre. So far as they go the following deductions can be made:

(i) That female relatives are predominantly affected with goitre of all types by 75 females to 13 males among the total of 88 affected relatives.

(ii) Of the 75 affected female relatives sisters were most frequently affected (43), followed by mothers (15), aunts (10), and daughters (7).

(iii) Males were seldom affected; brothers 12 times, fathers once, and sons not at all. It was noteworthy that the eight affected brothers of exophthalmic goitre patients all had exophthalmic goitre, while the four affected 


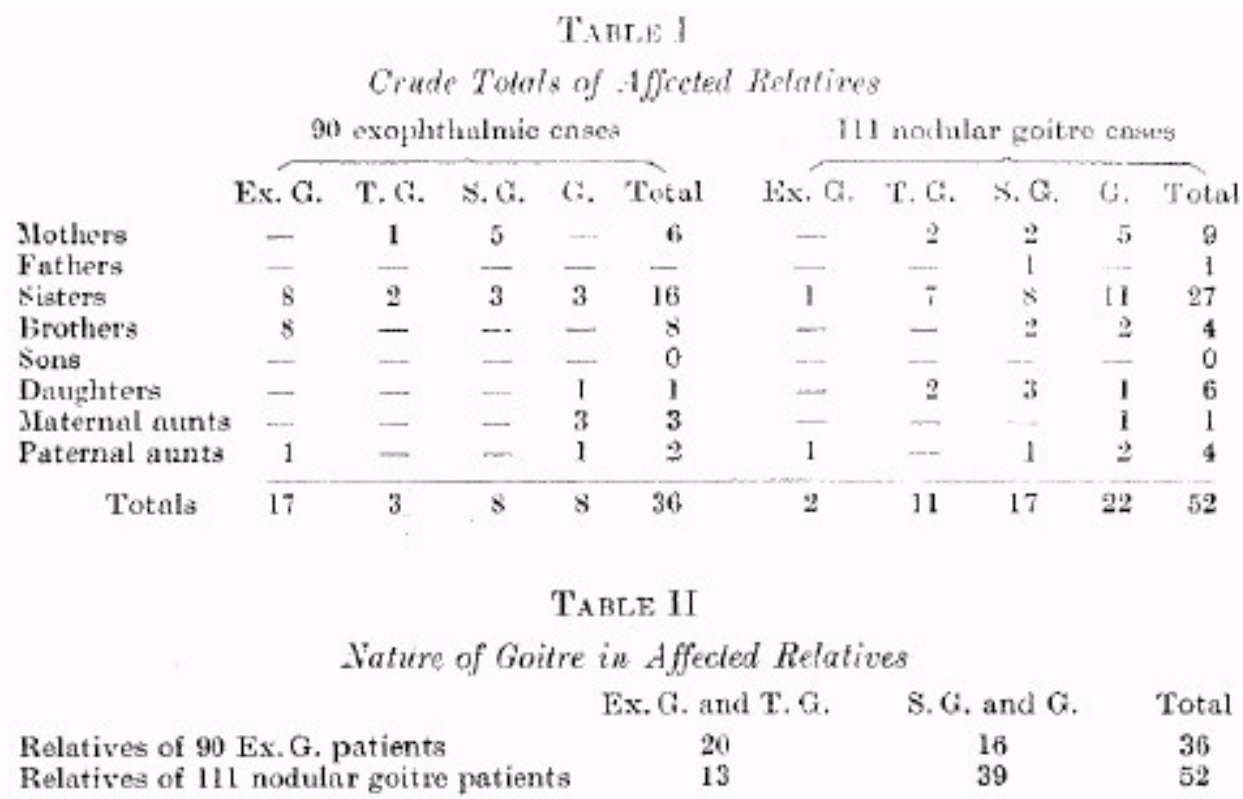

brothers of nodular goitre patients all had simple goitres or goitres not known to be toxic.

(iv) Patients suffering from exophthalmic goitre had more relatives with exophthalmic goitre than did patients with nodular goitres by 17 to 2 .

(v) Patients with nodular goitres had more relatives with simple goitres or goitres which were not known to be toxic than did patients with exophthat mic goitre by 39 to 16 .

(vi) The occurrence of toxic goitre, presumed not to be exophthalmic and probably to be secondary thyrotoxicosis, was commoner among the relatives of nodular goitre patients than among those of exophthalmic goitre patients by 11 to 3 .

The trend of this information is to confirm general experience that women suffer from goitres of all types more frequently than men, and to suggest that patients with exophthalmic goitre tend to have relatives affected by it, whereas patients with nodular goitres more often have relatives affected by simple or nondescript goitres. As regards comparison with relatives of nongoitrous and non-thyrotoxic individuals, it may be said that a certain number of goitres of all types occur by chance throughout the general population. It is probable that simple goitres, smooth or nodular, would out-number exophthalmic or toxic goitres because of their more numerous causes such as residence in an area of endemic goitre and the influence of pregnancy or sexepochs among women. It is therefore significant that the goitrous relatives of patients with exophthalmic goitre should have had exophthalmic goitre more frequently than simple goitre, and this suggests that a familial characteristic is present at any rate in some cases. Similarly, patients with nodular goitre had three times as many relatives with simple goitres or goitres which 
were not known to be toxic than did those with toxic or exophthalmic goitres, but for reasons to be discussed later this cannot be directly attributed to hereditary rather than to environmental causes. Although no figures are available for the incidence of goitre among the relatives of non-goitrous persons, it seems improbable that they would approach those of Table I, which shows 88 goitrous relatives in the families of 201 goitrous patients.

Study of affected siblings from available family trees. Family trees were available from 35 patients with exophthalmic goitre and from 50 patients with nodular goitre. There was a history of goitre among the siblings of 15 patients with exophthalmic goitre and of 17 patients with nodular goitre. This represents an incidence of goitre among siblings in 43 per cent. of the families of exophthalmic goitre patients and in 34 per cent. of the families of nodular goitre patients. Nineteen (12 per cent.) of the 160 siblings were affected by goitre, namely, 13 sisters ( 16 per cent. of the total of 79 sisters) and six brothers ( 7 per cent. of the total of 81 brothers). The types of goitre affecting the siblings are shown in Table IV. Of the 19 affected siblings, therefore, no less than 14 had exophthalmic goitre, two had toxic goitres, and all the affected brothers had exophthalmic goitre. Of the 214 siblings of 50 patients with nodular goitre, 12 (6 per cent.) were affected by goitre, namely, nine sisters ( 8 per cent. of the total of 111 sisters) and three brothers (3 per cent. of the total of 103 brothers).

The types of goitre affecting the siblings are shown in Table VI. Of the 12 affected siblings 10 had goitres which were simple or not known to be toxic. There was no example of exophthalmic goitre, but two sisters had toxic goitres. Table VII shows that sisters of exophthalmic goitre patients were affected by exophthalmic goitre or toxic goitre in 10 cases out of 13 , whereas seven of the nine affected sisters of nodular goitre patients had simple or nondescript goitres.

Table VIII shows that brothers were uncommonly affected by goitres of any kind, but those of exophthalmic goitre patients who were affected invariably had exophthalmic goitre. AH the affected brothers of nodular goitre patients had simple goitres or goitres not known to be toxic. If the affected siblings of exophthalmic goitre patients are taken together, 14 out of 19 had exophthalmic goitre and two had toxic goitre, while those of nodular goitre patients included only two with toxic goitre and none with exophthalmic goitre. These results confirm the deductions drawn from the crude figures of Table I and tend to show that there is a familial tendency for the occurrence of both exophthalmic goitre and for nodular and simple goitre, and that these tendencies are distinct. A familial tendency in either type of goitre is clearly not the rule, for siblings were affected in only 4.3 per cent. of the families of exophthalmic goitre patients, and in 34 per cent. of the families of nodular goitre patients. Nevertheless, these are considerable incidences, and in the case of exophthalmic goitre there is evidence to follow that a tendency or liability to this disease may exist in apparently unaffected relatives. 
TABLE III

Siblings of 35 Exophthalmic Goitre Patients

\begin{tabular}{lccr} 
& Males & Females & Total \\
In the 15 affected families & 32 & 35 & 67 \\
In the 20 unaffected families & $\underline{49}$ & $\underline{44}$ & $\underline{93}$ \\
\multicolumn{1}{c}{ Totals } & 81 & 79 & 160
\end{tabular}

TABLE IV

Types of Goitre in Siblings of Exophthalmic Goitre Patients

$\begin{array}{lccccc} & \text { Ex. G. } & \text { T.G. } & \text { S.G. } & \text { G } & \text { Tota } \\ \text { Sisters } & 8 & 2 & 3 & - & 13 \\ \text { Brothers } & \underline{6} & - & - & - & \underline{6} \\ \quad \text { Totals } & 14 & 2 & 3 & - & 19\end{array}$

TABLE V

Siblings of 50 Nodular Goitre Patients

\begin{tabular}{lccc} 
& Males & Females & Total \\
In the 17 affected families & 31 & 41 & 72 \\
In the 33 unaffected families & $\underline{72}$ & $\underline{70}$ & $\underline{142}$ \\
\multicolumn{1}{c}{ Totals } & 103 & 111 & 214
\end{tabular}

TABLE VI

Types of Goitre in Siblings of Nodular Goitre Patients

\begin{tabular}{lccccc} 
& Ex.G. & T.G. & S.G. & G. & Total \\
Sisters & - & 2 & 2 & 5 & 9 \\
Brothers & - & - & $\frac{1}{3}$ & $\underline{2}$ & $\underline{3}$ \\
\multicolumn{1}{r}{ Totals } & - & 2 & 3 & 7 & 12
\end{tabular}

Comparison of the Types of Goitres Affecting Siblings of Patients with Exophthalmic Goitre and Nodular Goitre

TABLE VII

Ex. G. T.G. S.G. G. Total

Sisters of exophthalmic goitre patients

Sisters of nodular goitre patients

8

2

- 13

$$
\text { Totals }
$$

-

$\frac{2}{4}$

$\frac{3}{2}$

$\frac{5}{5}$

TABLE VIII

Ex. G. T.G. S.G.

Brothers of exopthalmic goitre patients

Brothers of nodular goitre patients

Totals

\section{6}

6

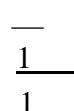

G. Total

- 6

$\frac{2}{2} \quad \frac{3}{9}$

Genetical Note by Professor R. A. Fisher

'Although no single-factor explanation can be accepted as a sufficient explanation even for exophthalmic goitre, one significant feature of the records is qualitatively of a kind to be expected from recessive inheritance and definitely opposed either to a purely environmental explanation or to 
inheritance of dominant type ; this is that in the pedigree record the proportion of sibs affected exceeds that of the parents. Sibs, it should be noted, are more likely to be missed through not yet having developed manifest symptoms and are not usually exposed to an environment more similar to that of the propositus than that of the parents. Yet the following tables ${ }^{2}$ show a clear disproportion which is statistically significant in both sexes.

\begin{tabular}{|c|c|c|c|}
\hline \multicolumn{4}{|c|}{ Table IX } \\
\hline \multicolumn{4}{|c|}{ Males } \\
\hline & Affected & Unaffected & Total \\
\hline $\begin{array}{l}\text { Brother's } \\
\text { Fathers }\end{array}$ & $\begin{array}{l}6 \\
0\end{array}$ & $\begin{array}{l}75 \\
90\end{array}$ & 81 \\
\hline $\begin{array}{l}\text { Fathers } \\
\text { Totals }\end{array}$ & 6 & $\widetilde{165}$ & $\frac{90}{171}$ \\
\hline \multicolumn{4}{|c|}{ Table $\mathrm{X}$} \\
\hline \multicolumn{4}{|c|}{ Females } \\
\hline & Affeeted & Unaffected & Total \\
\hline $\begin{array}{l}\text { Sisters } \\
\text { Mothers }\end{array}$ & $\begin{array}{c}10 \\
1\end{array}$ & $\begin{array}{l}69 \\
89\end{array}$ & $\begin{array}{l}79 \\
90\end{array}$ \\
\hline Totals & 11 & 758 & $\frac{80}{169}$ \\
\hline \multicolumn{4}{|c|}{ TABLE XI } \\
\hline \multicolumn{4}{|c|}{ Totals } \\
\hline & Affeeted & Unaffected & Total \\
\hline $\begin{array}{l}\text { Offispring } \\
\text { Parents }\end{array}$ & $\begin{array}{r}16 \\
1\end{array}$ & $\begin{array}{l}144 \\
179\end{array}$ & $\begin{array}{l}160 \\
180\end{array}$ \\
\hline Totals & 17 & $\overline{323}$ & 340 \\
\hline
\end{tabular}

In these tables the relatives noted as affected are those suffering from exophthalmic goitre, with whom have been included three cases of toxic goitre not positively known to be exophthalmic. These are one mother and two sisters. Even including these, however, the disproportionate frequency of affected sibs, as compared with parents, is clearly shown among the relatives of both sexes. No such contrast is to be observed among the relatives of patients suffering from nodular goitre, for example, for these 8 per cent, of mothers and 8 per cent, of sisters suffered from goitres, including all save exophthalmic cases in this classification. For exophthalmic therefore, though not for nodular goitre, there is evidence strongly suggestive of a single recessive factor favourable to the disease and perhaps necessary for its occurrence, but this does not mean that all recessives develop the disease. If this were so we should expect approximately one-quarter of the sibs to be affected and

\footnotetext{
${ }^{2}$ It should be noted that in these tables the mothers and fathers of all 90 cases of exophthalmic goitre are included because the information concerning them is considered to be reliable, but for the sibs, only those in the 35 families whose full trees are known are included. The 35 trees were influenced only by availability and not by any selection on account of defect. There is thus no reason to suppose that the proportions of affected and unaffected sibs would have been different had all 90 family trees been available.
} 
the tabular material set out above may be taken, on this interpretation, to imply that among females about half the recessives, and among males about one-quarter, develop manifest symptoms.'

The present study, then, has provided evidence suggesting that the familial occurrence of exophthalmic goitre is due to the inheritance of a liability to the disease, but there is none favouring heredity in nodular goitre. It remains, therefore, to discuss the factors accounting for the familial occurrence of nodular goitre and to consider the conclusions concerning exophthalmic goitre in the light of pre-existing evidence for its hereditary transmission.

\section{Factors in the familial Occurrences of Nodular Goitre}

The first point for emphasis is that nodular goitres (true adenomata excluded) are the outcome of simple goitres which almost universally become nodular with the passage of time. Thus discussion inevitably centres upon the causal factors of the initial simple goitre.

The role of iodine deficiency. Simple goitres may be either endemic or sporadic, and it seems probable that deficiency of iodine, either absolute or relative, is the basic cause of both, although this cannot be conclusively proved for sporadic goitres. Surveys in endemic goitre regions have, in general, shown that a dietary deficiency of iodine can be successfully correlated with the occurrence of goitre (McClendon and Hathaway, 1924 ; Hercus, Benson, and Carter, 1925 ; Hercus and Roberts, 1927) and that prophylactic administration of iodine to children in endemic goitre areas very greatly reduces the incidence of goitre (Marine, 1924; Hercus, Benson, and Carter, 1925). On the other hand, Orr (1931), from an iodine survey in areas of England and Scotland, could not show such a correlation. Nevertheless, he acknowledged the excellent results obtained in preventing goitre among children living in endemic areas by the administration of potassium iodide. The undeniably good results of prophylactic treatment carry great conviction, and the Goitre Sub-Committee of the Medical Research Council (1944) recently appealed for the addition of potassium iodide to table-salt as a national policy for the prevention of endemic goitre. It may therefore be accepted that an environmental and dietary deficiency of iodine causes simple endemic goitre.

Sporadic cases of simple goitre, on the other hand, cannot be explained on these grounds, for they occur in areas where iodine deficiency does not exist and in persons who are alone affected in a family or community living under the same conditions. A relative iodine deficiency has therefore been suggested in these cases, brought about by various agencies whose actions are at present unproven. Thus the simple goitres which not uncommonly occur during puberty or pregnancy in women are believed to be caused by demands for thyroxine, and so for iodine, whic h some thyroids cannot meet. The glands then undergo epithelial hyperplasia followed by permanent colloid 
change, and a simple goitre results. Infections are also thought to be capable of causing a simple goitre by interfering with the normal absorption or utilization of iodine by the thyroid gland. Thus the main causes of simple goitre, whether known or suggested, are thought to be due to iodine deficiency in some form, dependent either upon environmental or individual factors.

The role of heredity. If a family lives in an endemic goitre area for several generations the majority of members may be expected to possess goitres by

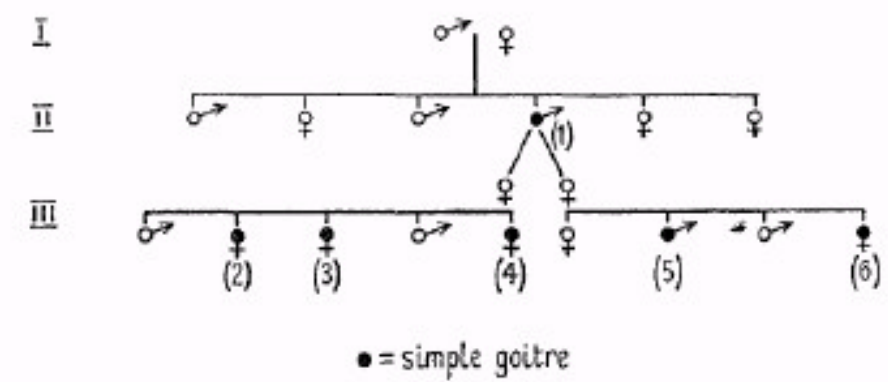

FIG. 1. The father (1), who came from non-goitrous stock, went to live at an early age in a mountainous district of Scotland where the drinking-water came from a running burn. He developed a simple goitre in early adult life and married twice. Both wives were non-goitrous and came from other parts of the country. By the first wife he had two sons and three daughters of whom the latter $(2,3,4)$ developed simple goitres. By the second wife he had two sons and two daughters of whom one son (5) and one daughter (6) developed simple goitres. Three affected daughters $(2,3,4)$ and one affected son (5) all married and left the family neighbourhood and their children (now adults) are all free from goitre.

reason of their environment. Yet the influence of intermarriage among goitrous persons living in an endemic area is also quoted as giving rise to the hereditary transmission of goitre or to its predisposition. Intermarriage undoubtedly occurs frequently in areas of endemic goitre because they tend to be remote or mountainous and often difficult of access. Joll (1932) mentioned this and stated that the existence of a hereditary transmission of goitre was favoured by the higher percentage of goitrous children born in endemic areas to parents who were born goitrous than to those of whom only one was affected. He added that, when goitrous parents migrated from endemic areas, the children born subsequently might be free from the disease and that the goitrous tendency disappeared in the course of one or two generations. Brain (1926) also rejected the assumption that environmental factors could alone explain the familial occurrence of simple goitre, because some families in endemic areas were disproportionately affected, because members born and brought up in non-endemic areas might also develop goitres, and because hereditary goitre was known to occur sporadically in non-endemic areas. He therefore postulated an inherited predisposition in the form of a defective utilization of iodine as an aetiological factor in some cases of simple goitre. Gardiner-Hill (1934) supported this hypothesis by recording a family affected by endemic goitre in which the emigration of several 
female members to non-endemic areas on marriage did not prevent the subsequent development of goitres in themselves and in two of their children who were born later. Murray and Wilson (1945) have also suggested that the same inherited defect in iodine utilization may exist in cases of deaf mutism which tend to occur in areas of England where the iodine-content of the water is low and endemic goitre or cretinism co-exist. There is thus a certain amount of evidence suggesting the presence of a hereditary factor in the occurrence of simple goitre, but its demonstration beyond doubt would be a formidable task in the presence of such a powerful environme ntal influence as iodine deficiency.

The family tree from a patient in the present series with a non-toxic goitre illustrates the difficulty in attributing a role to heredity as well as to iodine deficiency (Fig. 1).

The genetical evidence from the present study does not indicate any inherited trait in nodular goitre, but it does not, by virtue of its limited scope, exclude the possibility, and indeed this cannot be ignored. The concept of an inherited defect of iodine utilization resembles in some respects the longsuggested theory of inherited 'thyroid weakness' which was invoked to explain a variety of thyroid diseases and is discussed below in relation to exophthalmic goitre.

\section{Factors in the Familial Occurrence of Exophthalmic Goitre}

Exophthalmic goitre, in contradistinction to simple and nodular goitre, is not associated with a dietary deficiency of iodine and does not occur with undue frequency in any particular areas. A familial occurrence of the disease has never been successfully explained by the inheritance of a Mendelian dominant or recessive characteristic for the disease itself, and some authorities have fallen back upon the hypothesis of an inherited 'thyroid weakness' or 'defective thyroid stock'. This has been described in terms of a general defect of the thyroid gland and not as a predisposition to exophthalmic goitre in particular. Thus the sponsors of the hypothesis have been at pains to record families in which toxic goitre, simple goitre, nodular goitre, myxoedema, or cretinism have occurred in the same or succeeding generations. Souques and Lermoyez (1919) postulated 'une fragilité thyroidienne rendant le corps thyroide plus accessible, plus sensible aux diverses infections et intoxications' while Vallery-Radot (1922) and Rundle (1941), who were unable to demonstrate any Mendelian transmission of thyroid diseases, believed in a hereditary thyroid weakness which manifested itself by different thyroid disorders. Such an indefinite hypothesis as 'thyroid weakness' only begs the question as to whether exophthalmic goitre itself is inherited, and it can be criticized on several grounds. Firstly, families containing members affected by several thyroid disorders are not common and the diseases can often be explained by the presence of environmental factors which favour the development of simple goitre and its not infrequent sequels of nodular goitre and secondary thyrotoxicosis. One notable family in the 
present series included examples of exophthalmic goitre, retrosternal goitre, toxic goitre, disseminated sclerosis, myxoedema and pernicious anaemia, and bronchiectasis (Fig. 2). Such families are certainly not common enough to justify any generalizations.

A second major criticism of the 'thyroid weakness' theory is that cases of thyrotoxicosis in recorded family trees have not been separated into exophthalmic goitre (primary thyrotoxicosis) and secondary thyrotoxicosis. These two varieties of the disease differ significantly, and by definition, in

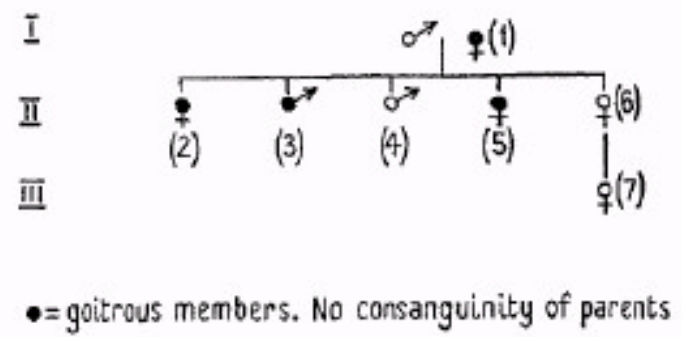

Fig. 2. (1) Died of toxic goitre.

(2) Retrosternal goitre removed at operation.

(3) Died of thyrotoxic heart failure.

(4) Died of disseminated sclerosis.

(5) Died after thyroideotomy for exophthalmic goitre.

(6) Has myxoedema and pernicious anaemia.

(7) Has bronchiectasis.

that exophthalmic goitre occurs in previously non-goitrous individuals, whereas secondary thyrotoxicosis supervenes in persons already possessed of a simple goitre which with the passage of time has usually become nodular. This cardinal difference at once confuses any questions of inheritance when both types are taken together, because simple goitre, as has already been suggested, can mainly be accounted for by environment or individual factors, while no such factors are known to exist in exophthalmic goitre, in which, however, there is evidence in favour of an inherited liability. Thus to include both types of goitre and attribute them to heredity, ' thyroid weakness', or any common cause is to invite erroneous conclusions.

The results of the present study have, in fact, gone far to show that there is little tendency for the relatives of patients with exophthalmic goitre to be affected by simple goitre, and conversely that patients with nodular goitre, the outcome of simple goitre, have very few relatives with exophthalmic goitre. That patients and their affected relatives should thus tend to have the same type of goitre is not only in favour of different causal factors in each type, but also is against any general thyroid weakness which should manifest itself by a wider variety of thyroid disorders. Furthermore, exophthalmic goitre is no longer to be regarded as a purely thyroid defect, but as a syndrome or mosaic of symptoms whose ultimate cause may well reside outside the thyroid gland. For these reasons, therefore, the hypothesis of an inherited thyroid weakness can be rejected as a factor in the production of exophthalmic goitre. 


\section{The Inherited Liability to Exophthalmic Goitre}

The present study has confirmed a familial occurrence of exophthalmic goitre and the genetical evidence points to the inheritance of a recessive characteristic which confers a liability to develop the disease and is, perhaps, necessary for its occurrence. Consideration of the nature and clinical recognition of this inherite d liability lies beyond the scope of the present paper, and indeed the matter is largely conjectural, but a brief suggestion is permissible. It is possible that the inherited liability to exophthalmic goitre may be a personality-type characterized by a constitutional nervous instability affecting particularly the autonomic nervous system. This was suggested by Warthin (1928) in association with hyperplasia of the thymus and lymphoid tissues, while Eason (1927) believed that it occurred in persons of particular bodily builds, but general experience does not bear out the occurrence of exophthalmic goitre in persons with any particular anatomical constants. Moschcowitz (1930) stressed an inherited constitutional nervous instability in persons suffering from exophthalmic goitre, although he gave no genetical details. He believed that it might remain latent so that all those members of a family who possessed it need not necessarily develop exophthalmic goitre, although they might have various nervous manifestations. With some other additional exciting factor, however, such as psychic trauma, infection, or sex-epoch, florid exophthalmic goitre could develop. More recently Moschcowitz and Bernstein (1944) have identified this constitutional nervous instability with neurocirculatory asthenia, but this cannot be unreservedly accepted. However, the recessive characteristic detected in the present study, which confers a liability to exophthalmic goitre, might be the same as that suggested by Moschcowitz and the possibility merits further investigation. Halliday (1943) has recently drawn attention to the psychosomatic affections, of which exophthalmic goitre is one, and future studies of the disease must include a more extended inquiry into the underlying personality and constitution of those affected by it.

\section{Summary}

1. The familial or hereditary occurrence of goitre has been investigated in 90 cases of exophthalmic goitre and 111 cases of nodular goitre.

2. The goitrous relatives of patients with exophthalmic goitre were pre dominantly affected by exophthalmic goitre.

3. The goitrous relatives of patients with nodular goitre were almost exclusively affected by simple or nondescript goitre.

4. Genetical evidence strongly suggests the inheritance of a recessive factor favourable to the occurrence of exophthalmic goitre.

5. There is no evidence from this study of an inherited trait in nodular goitre, but the possibility of it cannot be ignored.

6. It is suggested that the inherited recessive factor in exophthalmic goitre may prove to be a personality-type or a constitutional nervous instability. 
The work for this paper was largely carried out during the tenure of the Leverhulme Research Scholarship of the Royal College of Physicians. It is a pleasure to thank the honorary medical and surgical staffs of Addenbrooke's Hospital, Cambridge, for free access to cases under their care.

\section{REFERENCES}

Atkinson, F. B. R. (1938) Brit. Journ. Child. Dis. 35, 165.

Brain, W. R. (1926-7) Quart. Journ. Med. 20, 303.

Climenko, H. (1920) Arch. Neurol. Psychiat. 3, 530.

Cockayne, E. A. (1928) Arch. Dis. Child. 3, 227.

Eason, J. (1927) Exophthalmic Goitre, Edinb.

Gardiner-Hill, H. (1934) in The Chances of Morbid Inheritance, ed. C. P. Blacker, Lond. 318.

Halliday, J. L. (1943) Lancet, 2, 692.

Hercus, C. E., Benson, W. N., and Carter, C. L. (1925) Journ. Hyg. 24, 321.

-----and Roberts, K. C. (1927) Ibid. 26, 49.

Joll, C. A. (1932) Diseases of the Thyroid Gland, Lond.

Mackenzie, H. (1916) Lancet, 2, 815.

Marine, D. (1924) Medicine, 3, 453.

McClendon, J. F., and Hathaway, J. C. (1924) Journ. Amer. Med. Assn. 82, 1668.

Means, J. H. (1937) The Thyroid and its Diseases, Phila. and Lond.

Medical Research Council, Goitre Sub-Committee, Memorandum (1944) Lancet, 1, 107.

Moolten, R. R., and Bruger, M. (1942) Arch. Surg. 45, 623.

Morrison, H. (1928) New Eng. Journ. Med. 199, 85.

Moschcowitz, E. (1930) Arch. Int. Med. 46, 610.

— and Bernstein, S. S. (1944) Amer. Heart Journ. 28, 177.

Murray, M. M., and Wilson, D. C. (1945) Nature, 155, 79.

Orr, J. B. (1931) Med. Res. Coun. Spec. Rept. Ser. No. 154.

Pern, S. (1911-12) Australian Med. Jour. N.S. 1, 516.

Rundle, F. F. (1941) Lancet, 2, 149.

Souques and Lermoyez, J. (1919) Rev. Neurol. 35, 20.

Vallery-Radot, P. (1922) Lancet, 1, 24.

Warthin, A. S. (1928) Ann. Int. Med. 2, 553.

Wild, R. B. (1886) Brit. Med. Journ. 1, 1021.

\section{ADDENDUM}

An important monograph entitled Heredity in Graves' Disease (E. Bartels, Copenhagen, 1941) recently became available, but could not be commented upon in the text of our paper. The author's material comprised 197 cases of Graves's disease and 'toxic adenoma' of the thyroid (toxic nodular goitre) from Copenhagen. Consanguineous marriage in parents was recorded once. In 69 cases only was the diagnosis definitely Graves's disease; and a family history of goitre was noted in 42 per cent. of these. Bartels detected a recessive characteristic for inheritance of Graves's disease which was partially sex-limited to women with a manifestation in them of 70 to 80 per cent. In respect of Graves's disease, therefore, the results of our study corroborate Bartels's findings. We feel, however, that the evidence for recessive inheritance has been obscured by the inclusion of a large number of nodular goitre patients both among the relatives and the propositi. It is of interest to note that the occurrence of Graves's disease and goitre among the female population of Copenhagen was estimated at 0.4 and 1.1 per cent. respectively. 